\title{
O Geógrafo Horacio Capel: estudos urbanos e a história do pensamento geográfico
}

\section{Felipe Ramão}

\section{(2) OpenEdition}

Journals

\section{Edição electrónica}

URL: http://journals.openedition.org/espacoeconomia/3093

DOI: 10.4000/espacoeconomia.3093

ISSN: 2317-7837

\section{Editora}

Núcleo de Pesquisa Espaço \& Economia

\section{Refêrencia eletrónica}

Felipe Ramão, "O Geógrafo Horacio Capel: estudos urbanos e a história do pensamento geográfico », Espaço e Economia [Online], 11 | 2017, posto online no dia 07 abril 2018, consultado o 30 abril 2019. URL : http://journals.openedition.org/espacoeconomia/3093 ; DOI : 10.4000/espacoeconomia.3093

Este documento foi criado de forma automática no dia 30 Abril 2019.

(C) NUPEE 


\section{O Geógrafo Horacio Capel: estudos urbanos e a história do pensamento geográfico}

Felipe Ramão

URTEAGA, Luis e CASALS, Vicente (eds). Horacio Capel, geógrafo. Barcelona : Publicacions i Edicions de la Universitat de barcelona, $1^{\mathrm{a}}$ edicion, 2015

Capa

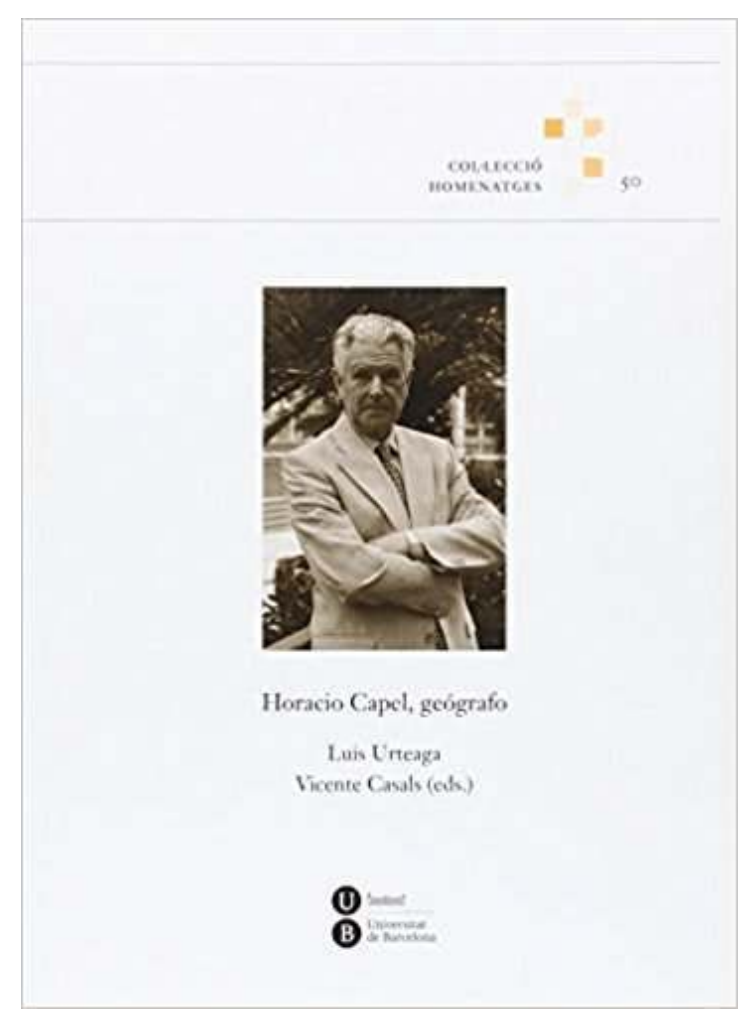

Foto da Capa 
2 O livro é uma justa homenagem ao geógrafo espanhol Horacio Capel, que desenvolve uma importante obra desde a década de 1970, sendo reconhecido nos últimos anos como uma das figuras mais proeminentes da Geografia europeia, recebendo vários prêmios, dentre os quais o Vautrin Lud, em 2008. Autor de uma extensa bibliografia, Capel se dedica ao campo da Geografia Humana, privilegiando em grande parte da carreira os estudos urbanos e ainda produz importantes análises sobre a história do pensamento geográfico.

Nascido em Málaga - Espanha em 1941, o autor homenageado cursou licenciatura em Filosofia e Letras - especialidade em História na Universidade de Murcia. Professor auxiliar com apenas 23 anos, em 1966 se mudou para Barcelona, onde concluiu seu doutorado em 1972, sob a orientação do nobre professor Joan Vilà Valentí, figura ímpar na Geografia espanhola.

4 O livro é extenso, um pouco mais de 660 páginas, mantém partes comuns em livros de homenagem, com relatos e recordações de professores e amigos, destacando as principais características, qualidades, a importância do professor e do homem Horacio Capel, e, a influência e relevância da obra. $O$ avanço desse livro é justamente, em três seções, utilizar Capel enquanto método, isto é, interpretam o urbano em dois momentos da carreira do autor (década de 1970 e 1990), utilizando os seus conceitos, fundamentos teóricos e metodológicos, e, interpretam a história do pensamento geográfico, de igual forma.

5 Logo, mais do que uma referência e uma homenagem a uma brilhante carreira, de um professor e pesquisador generoso e dedicado, com uma obra vistosa e importante na Geografia de muitos países, o livro nos mostra o quanto o pensamento de Horacio Capel é útil e necessário na compreensão da realidade do mundo atual, e, que revisitar a obra do autor é um exercício obrigatório para os geógrafos da nova geração.

6 A estratégia utilizada na resenha, por conta principalmente da extensão e complexidade do livro, será a divisão em três momentos: [I] identificar a estrutura e a divisão do livro [II] mostrar a cronologia da carreira de Capel, por entender que a cronologia tem um teor de apresentação do autor, mesmo que no livro esteja localizada na parte final [III] e analisar as seções, a parte mais extensa e ainda subdividida em três partes, correspondendo ao corpo teórico-metodológico e intervalos de tempo na carreira de Capel.

\section{ESTRUTURA E DIVISÃO DO LIVRO}

7 A Seção I, intitulada "Ciudad, território, forma", referente ao início do trabalho do geógrafo H. Capel, dedicado à Geografia Urbana, uma fase mais crítica do autor, no contexto turbulento do mundo e da Europa da década de 1970. Os principais temas abordados nos artigos são: a morfologia das cidades, técnicas e infraestruturas urbanas, a relação entre o urbano e o social, com leituras específicas da cidade americana e de Barcelona.

8 A Seção II, intitulada "Teoría e historia de La Geografía", artigos que tratam da segunda fase de sua carreira, onde se dedica a questões do pensamento geográfico, tendo como marco o ano de 1979, que se consolida na década de 1980. A seção conta com artigos voltados para: noções teóricas e metodológicas das ciências, de que forma a Geografia se transforma e se relaciona com outras ciências sociais, o papel acadêmico do autor e a questão da educação.

9 A Seção III, intitulada "Saberes, Prácticas, representaciones", referente ao seu retorno a problemática urbana na década de 1990, a partir de novos elementos, interessando-se 
principalmente pela inovação tecnológica, as redes técnicas e infraestruturas urbanas, contando com artigos sobre a função do Estado, a participação e o controle social, e, uma leitura importante sobre o patrimônio.

10 A Seção IV retoma alguns livros mais influentes do autor, com um objetivo de produzir um balanço histórico, recuperar e avançar acerca de questões do capitalismo e o espaço urbano, a filosofia e as ciências na sua relação com a Geografia contemporânea, entre outros aspectos mais específicos.

11 A Seção V é dedicada a uma série de histórias e lembranças, de cunho mais pessoal, sobre Horacio Capel, com destaque para o depoimento do seu professor, orientador e figura ilustre da Geografia espanhola, Joan Vilà Valentí, entre outros professores, amigos e orientandos que acompanharam a brilhante carreira desse geógrafo.

12 A Seção VI é uma espécie de complemento, traçando uma cronologia intelectual e uma seleção de suas publicações.

A Seção VII é dedicada a fotografias de diferentes momentos da carreira e da vida de Horacio Capel.

\section{A CRONOLOGIA INTELECTUAL DE HORACIO CAPEL}

14 Alguns pontos são centrais para compreender a cronologia intelectual de Horacio Capel. 0 primeiro ponto, é creditar como um fator decisivo para a construção do seu pensamento uma rede de influências, que articula a geografia espanhola, francesa, anglo-saxã e alemã, a sociologia urbana, e a filosofia também ligada à questão urbana; o segundo ponto, é compreender que a obra de Capel é extremamente dinâmica além de ampla, o que mostra uma evolução do pensamento do autor no decorrer das décadas, a necessidade de uma auto-avaliação permanente do discurso e da produção, sua mobilidade por grupos e universidades, o que mostra sua rede de trabalho (com parcerias e orientações); o terceiro ponto é sua interação com os avanços tecnológicos e com a comunicação, preocupando-se com a publicação dos seus escritos, e, principalmente, se forma generosa, com o conhecimento produzido por vários autores, através das revistas e eventos organizados pelo autor; o quarto ponto, é que mesmo tratando de outros temas, o autor é referenciado pelo seu trabalho com o urbano, que apresenta de forma geral duas grandes fases em contextos distintos, onde em grande parte aparece um autor crítico diante de um processo de urbanização cada vez mais desigual e avassalador, contudo, em toda a sua obra, aparece um espaço para a utopia na cidade.

\begin{tabular}{|l|l|}
\hline \multicolumn{2}{|l}{ SÍNTESE DA CRONOLOGIA INTELECTUAL DE HORACIO CAPEL } \\
\hline 1966 & $\begin{array}{l}\text { Professor titular em Barcelona } \\
\text { Inicia o contato com geógrafos de CAEN (Universidade do Norte da França) } \\
\text { Criação do Departamento de Geografia na Universidade de Barcelona }\end{array}$ \\
\hline 1967 & Criação da Revista de Geografia da Universidade de Barcelona \\
\hline 1972 & Obtêm o doutorado em Filosofia e Letras seção Geografia na Universidade de Barcelona com a tese A rede urbana espanhola , 195 \\
\hline 1973 & Primeiros questionamentos sobre a validade da Geografia Quantitativa \\
\hline
\end{tabular}




\begin{tabular}{|c|c|}
\hline 1974 & Reflexão sobre as correntes geográficas existentes (regional, quantitativa, radical), os métodos, relações com outras disciplinas, \\
\hline 1975 & Publica Capitalismo y morfologia urbana que alcançará seis edições \\
\hline 1976 & Inicia a revista Geo Crítica \\
\hline 1982 & Com Luis Urteaga publica Las Nuevas Geografías \\
\hline 1986 & Criação do Departamento de Geografia Humana da Universidade de Barcelona \\
\hline 1987 & Publica Geografia Humana y ciências sociales. Una perspectiva histórica. \\
\hline 1994 & Com Mercedes Tatjer publica La organizacíon de la rede telegráfica espanõla \\
\hline 1996 & Inicia o portal Geocrítica \\
\hline 1997 & Série de publicações sobre o tema da imigração \\
\hline 1999 & Dirige o primeiro Colóquio Internacional de Geocrítica - Universidade de Barcelona \\
\hline 2002 & Publica o primeiro volume de La morofología de las ciudades. I Sociedad, cultura y paisaje urbano \\
\hline 2005 & Segundo volume de "La morofología de las ciudades. II Aedes facere: técnica, cultura y clase social en la construcíon de edifícios' \\
\hline 2013 & Publica o terceiro volume de de La morofología de las ciudades III Agentes urbanos y mercado immobiliario \\
\hline 2014 & Publica o livro Patrimonio: a construcíon del passado y del futuro \\
\hline
\end{tabular}

15 Tabela 1. Síntese da cronologia intelectual de Horácio Capel, apresentada por Núria Benach e Alexandre Cumplido (2015). Organização: autor, 2017.

\section{ANÁLISE GERAL DAS SEÇÕES}

Seção I - Ciudad, território, forma.

1. Carles Carreras i Verdaguer, no artigo "La morfología de las ciudades", aponta como a concepção de morfologia urbana de Capel está alicerçada em referências da Geografia de vários países, de autores das ciências sociais e filomarxistas, e, simboliza uma leitura crítica da realidade, vinculada diretamente ao aspecto social e a pontos basilares do movimento de renovação da Geografia. Destarte, Capel merece destaque por apresentar uma relação entre a geomorfologia e a geografia urbana, considerando diversos agentes, processos e articulações.

18 Segundo Verdaguer, a construção e o comando da revista Geo crítica em 1976 é um ponto essencial para compreender a carreira de Capel, relevando o excelente referencial teórico e a divulgação de trabalhos de geógrafos de diversos países, com as mais diferentes contribuições. No decorrer do livro, diversos autores irão corroborar com essa perspectiva. 
19 2.Vicente Casals Costa, no segundo artigo da seção intitulado "Barcelona", trata do importante livro de Capel "Capitalismo y morfologia urbana em Espãna", destacando suas edições nas décadas de 1970, 1980 e 1990, e, especificamente o conceito de agentes urbanos, a partir do contexto da Espanha. Nesse balanço teórico e metodológico de Capel no decorrer das décadas, Costa afirma que o teor mais crítico das análises de Capel vistos na década de 1970 sobre o urbano, diminui no começo da década de 1990, substanciado e influenciado em parte sobre os efeitos das Olimpíadas e o projeto de reestruturação de Barcelona. O vigor crítico de Capel retornaria, segundo o autor, em 2004, no Fórum das Culturas, e, posteriormente em um livro sobre Barcelona (2005) "El modelo Barcelona: un examen crítico", entre outros artigos.Costa ainda faz um longo e relevante debate sobre o conjunto de três livros de Capel intitulado "Morfología de las ciudades" (2002, 2005 e 2015), identificando os principais temas e as abordagens de Capel sobre diversas problemáticas.

20 3.Eulalia Ribera Carbó, no artigo La ciudad americana, trata da análise de Capel sobre o fenômeno urbano na cidade americana, a partir de inúmeros artigos, e, a rede de trabalho que articula Capel, professores e alunos principalmente dos países ibero-americanos. A produção do geógrafo espanhol, assim como a participação em conferências e eventos fora da Espanha, solidifica uma aproximação com estudantes argentinos, chilenos, mexicanos, colombianos e brasileiros.

21 Carbó explora o retorno de Capel ao urbano, em um contexto de globalização, evolução da tecnologia , desenvolvimento territorial das cidades e liberalização da economia, com mudanças no papel e na ação do Estado. Outro destaque, é a análise comparativa entre as cidades da Espanha e de outros países europeus com os países subdesenvolvidos americanos, conduzidas por Capel, acerca do processo de urbanização e constituição de metrópoles, o mundo do trabalho, a lógica da produção e do mercado imobiliário, a secundarização do fator social, entre outros pontos.

22

Arroyo Huguet, no artigo "Redes técnicas e infraestructuras urbanas", trata das contribuições de Horacio capel sobre o tema Tecnologia e cidade. A autora parte do contexto da década de 1970, relacionado o tema central com a discussão de redes e de políticas públicas.

Em um contexto amplo, há mudanças nas análises entre tecnologia e cidade: em um primeiro momento, a tecnologia aparece como algo externo à cidade, mas com a capacidade de modelar a vida urbana e os comportamentos da população, posteriormente avança na consideração de diferentes interesses econômicos, políticos e sociais, inclusos na discussão, e, alcança a análise de desenvolvimento da cidade, onde emerge a questão da infraestrutura urbana.

Segundo a autora, o objeto central para Capel é a cidade, logo temas como tecnologia, infraestrutura urbana e redes são vistos a partir da discussão da cidade.Apesar das redes técnicas, principalmente em um contexto das últimas três décadas, estarem estabelecidas em muitos momentos a partir da combinação entre o público e o privado, para Capel, o controle dessas redes deve ser pelo Estado, como uma forma de evitar desigualdades territoriais e monopólios da iniciativa privada. Assim, seria possível destacar pontos centrais da discussão sobre cidade em Capel, que considera o papel da tecnologia: [I] os meios de comunicação [II] a hierarquia urbana [III] estrutura espacial das redes, a partir do controle do território por diversos agentes [IV] o impacto das novas tecnologias sobre 
a morfologia urbana e sobre a vida social [V] o desenvolvimento das cidades e os efeitos na população urbana.

Por fim, a autora destaca trabalhos mais recentes de Capel (2000, 2011 e 2013) onde o autor aprofunda a discussão de redes e serviços, o papel do Estado e o processo de privatização, indicando uma nova organização do espaço, com referência nas áreas metropolitanas, tratando ainda de gestão, hierarquia urbana e modernização das cidades.

27 5.Jordi Martí-Henneberg e Rafael Giménez Capdevila, no artigo "Ciudad , transporte y redes", partem do mesmo princípio de Huguet, no artigo anterior, a compreensão que o tema cidade é central para o Capel, contudo, os autores irão destacar a questão das redes e do transporte.

28 Segundo os autores, a questão das redes tem sido importante para Capel desde o começo de sua carreira, sendo fundamental na construção do espaço urbano. Já em 1975, essa importância das redes é percebida no livro Capitalismo y morfología urbana en España, ao tratar fundamentalmente das estratégias de empresas no espaço, o que décadas mais tarde, já no século XXI, assumirá novos contornos em um cenário de privatização e esfacelamento da ação do Estado.

29 Especificamente da rede ferroviária, Capel compreende em vários trabalhos as estações ferroviárias enquanto agentes dinamizadores e a via férrea como fronteira da expansão urbana. A ferrovia é vista a partir da sua relação e dos deus impactos na morfologia urbana, o que diretamente se coliga com questões referentes ao trabalho, serviços e planejamento urbano.

Por fim, os autores sinalizam uma série de trabalhos recentes, que são inspirados na obra de Capel, especificamente do programa da Universidade de Lleida sobre a influência da estação ferroviária na evolução da morfologia urbana desde o século XIX, partindo de pontos centrais como: [I] a disposição espacial das estações ferroviárias [II] as características específicas das cidades impactadas pela ferrovia [III] o uso da cartografia e do sistema de informação geográfica (SIG) e outras ferramentas [IV] o processo de urbanização e ocupação dos espaços a partir das ferrovias [V] a relação entre o público e o privado.

31 6.Pere López Sánchez, no artigo "Acotar los espacios. Los márgenes de las periferias", apresenta uma análise concisa, e, inclusa na obra de Capel, sobre os espaços da cidade, construindo um balanço sobre o crescimento urbano, os custos sociais e a relação entre centro e periferia. O papel do Estado aparece mais uma vez, (o que de fato é uma característica marcante da obra de Capel), junto com as contradições da grande metrópole, representada enquanto um centro econômico e de referência, e, quanto um espaço de exclusão e resistências.

32 Dois pontos importantes que Sánchez aborda é que o aprofundamento da exclusão social mostra a incapacidade do Estado, e, ao mesmo tempo, o resultado de políticas neoliberais, e, que a periferia passa a ser também um espaço da cidade, que parece cada vez mais dividida, na cidade do privilégio e cidade do gueto, cidade do consumo das elites e a cidade da exclusão.

33 As formas de lutas nesse sentido também se multiplicam, e, especificamente no caso de Barcelona (metrópole de referência, bela e atrativa), a resistência de muitos bairros contra a exclusão é fundamental para compreender a dinâmica urbana. A luta pelo direito à cidade se realça, e, em 2014 em Barcelona, a dualidade da cidade se reafirma mais uma vez, com um novo planejamento estratégico do governo, que reconhece a cidade a partir 
do empreendedorismo e de uma metrópole inovadora, concomitante às jornadas de discussão de bairros cooperativos, com projetos, iniciativas e de integração territorial, visando a articulação entre coletivos e indivíduos, mantendo a identidade e memória dos bairros, consequentemente, partindo de um conceito de cidade distinto.

7. Hugo Gaggiotti encerra a seção 1, com o texto "Lo urbano como organizador simbólico de lo social" O autor apresenta pontos de inovação da obra de Capel acerca do urbano, principalmente na relação da cidade com um plano imaterial; considerando os símbolos, os discursos, na produção e reprodução do espaço urbano; identificando essa relação na obra de Capel e na obra de outros autores, sobretudo, que são referenciais teóricos para o geógrafo espanhol, que aponta que o urbano vai além da Geografia. Dessa forma, a concepção de urbano de Capel é ampla, considerando a importância do fator social, e, crédulo que a discussão é parte fundamental do pensamento científico, talvez o que faça o geógrafo ampliar o seu leque de discussão para a filosofia, sociologia, antropologia, entre outras ciências.

Segundo Gaggiotti, o mundo urbano burguês estudado por Capel emerge através de uma substancial produção, seja dos serviços urbanos criados pela burguesia, os modelos de organização burguesa da sociedade e o imaginário tecnológico burguês. Nesse sentido, a análise de Capel se aproxima do segundo espírito do capitalismo de Boltanski e Chiapello, que ressaltam a tecnologia, a racionalidade, a produção em massa, o progresso, etc.

Por fim, temos em leituras mais recentes de Capel, com referência principal ao Congresso Internacional "Geocrítica" em 2014, e o aprofundamento da leitura sobre a cidade em seu sentido simbólico. A cidade é analisada como um resultado e um produtor de imagens e imaginários, imersas no contexto do capitalismo da globalização, contudo, advertindo que o poder simbólico da cidade seria como uma forma de impor poder, de controle social, de imposição de cima para baixo, sem omitir as formas de resistências.

\section{AUTOR}

\section{FELIPE RAMÃO}

Professor da rede estadual de educação no estado do Rio de Janeiro e doutorando no Programa de Pós-Graduação em Políticas Públicas e Formação Humana - PPFH/UERJ 